\title{
Exploring young people's emotional well-being and resilience in educational contexts: a resilient space?
}

\author{
Authors: Cocking C (PhD, RMN), Sherriff N (PhD), Aranda K (PhD), \& Zeeman L (PhD, RMN) \\ Affiliation: University of Brighton, School of Health Sciences. \\ Contact details: Dr Chris Cocking, c.cocking@brighton.ac.uk; Tel: 0044 (0) 1273 644510;
}

\begin{abstract}
The term 'resilience' is pervasive in narratives of young people's emotional well-being. However, the meaning it has for those it describes, is perhaps less well understood. Resilience was investigated as part of an engagement exercise into health improvement commissioning in educational contexts in the South East of England. 109 young people in total were involved, and this paper reports data collected from two areas that were explored, comprising a sub-set of 58 participants: Emotional Well-being and Resilience (EWR) ( $n=23)$; and the Whole School Approach (WSA) ( $n=35)$. It was apparent that whilst not all participants engaged with the term 'resilience' itself, they nevertheless often adopted creative individual and collective strategies to protect and enhance their emotional well-being. Furthermore, participants reported a sense of resilience that arose from a shared sense of adversity that helped strengthen collective support and solidarity, thus supporting previous work on emergent collective resilience. Theoretical and practical implications are discussed, along with a recommendation for more participatory research, so that young people can be more confident that their views are being considered within such exercises.
\end{abstract}

Keywords: Young People; mental health; resilience; social psychology; education

\section{Introduction:}

The emotional well-being of young people is recognised as a global health priority (Stengård \& Appelqvist-Schmidlechner, 2010), and there is a growing awareness of the difficulties they can experience as they age. For instance, a recent study of emotional well-being in school children in England (Weare, 2015) suggested that up to $10 \%$ may have mental health and/or emotional problems. Furthermore, the National Society for the Protection of Cruelty to Children reported a $43 \%$ rise year on year in young people admitting during counselling that they had attempted suicide (NSPCC, 2014). So, there is a clear need to address this issue. It has long been recognised that the mental health needs of young people are frequently neglected (e.g. Weare, 2015; Wells et al., 2003), and this is especially important in educational contexts, given that promoting physical and mental health helps reinforce children's educational achievement; which in turn, can improve their well-being (Brooks, 2012). Building upon Marmot (2010), the Department of Health (DH) England argued that early interventions could promote general mental well-being, and they should begin at school if they are to be effective (DH, 2015 , p.36). So, schools have a responsibility to promote the emotional well-being and resilience of young people- something that is increasingly recognised by practitioners (Theron, 2016). 


\section{Promoting resilience in young people:}

'Resilience' is a concept that is used in many different contexts with varying definitions, but when used in relation to young people, it usually refers to their ability to cope with the challenges they face as they mature ${ }^{1}$. For instance, Public Health England (2014) describes resilience as; "the capacity to 'bounce back' from adverse experiences and succeed despite adversity" p 6. Current theoretical perspectives (e.g. Aranda et al, 2012; Aranda \& Hart, 2015; Cocking, 2016) argue for more collective and/or communityfocused approaches, as opposed to earlier approaches that viewed resilience as more of an individual quality. Furthermore, it is now more common to consider resilience as a dynamic process that individuals and groups experience, as opposed to a fixed or inherent trait (Glasgow Centre for Population Health, 2014), and there is a growing recognition that schools should encourage the emergence and maintenance of resilience within educational contexts. For instance, Sherriff, et al.'s (2015) engagement exercise into health provision in English schools found that: 1) schools occupy a key place to build resilience among children and young people; 2) they should adopt a Whole School Approach (WSA) ${ }^{2}$ to overall wellbeing (Department for Education [DFE], 2015; Langford et al., 2014; Marmot, 2010), and; 3 ) that there are a range of ways in which local authorities can support and encourage schools to take such action (Allen, 2014). Therefore, schools have an important role in encouraging young people's resilience and their subsequent learning and cognitive development will be influenced heavily by such emotional health and wellbeing. However, it is also important to bear in mind that promoting resilience in schools could benefit all members of the school community, as highlighted by Young Minds in Schools (2015); "Resilience is about all children (and adults), not just those who are considered vulnerable and is therefore a whole school issue" p.25.

\section{Broader social contexts:}

Recent theoretical developments in resilience (e.g. Aranda \& Hart, 2015; Cocking, 2016; Hart et al, 2016) and local government initiatives (Lyons, 2016, p.16) argue that individual frameworks should consider not only the broader social contexts in which resilience can develop in response to adversity, but also have a greater emphasis on promoting structural change to achieve social justice, thus complementing recent calls for more 'critical resilience' (Traynor 2018, p.7). This is important because adopting individualistic approaches risks 'blaming' individuals for their own adversity (Sherriff et al, 2015, p.74), and could also shift the emphasis onto encouraging individual responsibility for coping in adverse environments rather than questioning and/or tackling the wider determinants of inequality (e.g. Bottrell, 2013; de Lint \& Chazal, 2013). Such theoretical advances support the notion that specific initiatives to promote emotional wellbeing and resilience (EWR) in schools need to be perceived as additional to (and not instead of) health improvement initiatives adopting WSAs that look at creating healthy policies, and environments for all (e.g. Weare, 2015). To this end, Aston (2014) suggested an ecological framework for mental health promotion in schools that operates on the macro, meso and micro levels: wider societal influences; the Whole School Approach; and encouraging positive individual

1 See Aranda \& Hart (2015) for more detailed coverage of the different possible definitions of resilience

2 The WSA is conceptualised as involving action in three areas within schools: a) the formal health curriculum; b) the ethos and environment of the school and; c) engagement with families and communities (Langford et al, 2014). 
mental health. Moreover, while resilience programmes should be universally available, they are also commonly targeted towards reducing the gradient in health inequalities 'with a scale and intensity that is proportionate to the level of disadvantage' (p.16: Marmot, 2010)- a concept known as proportionate universalism. Adversity in society is rarely equally distributed, and those facing the most hardship, are often the least likely to have the necessary resources available to be able to develop more resilient responses. It is therefore necessary to explore ways of enhancing individual young people's emotional well-being within these broad social contexts. One possible strategy may be to create an environment within schools that values all pupils and encourages a sense of belonging, as such connectedness can help create the conditions in which young people feel able to talk about their problems in a nonstigmatising way (e.g. DFE, 2015; Rowe and Stewart, 2009; Weare, 2015 p.8). The concept of belonging features in resilience frameworks (e.g. Hart et al, 2007) and is also a recognised protective factor for mental health in schools (Stewart-Brown, 2006), with recent evidence showing that framing resilience within a team-based perspective can be beneficial (Eames et al, 2016). However, notions of belongingness in relation to resilience are often grounded in individualist perspectives from developmental psychology, and links with broader social psychological approaches have so far received less attention. Therefore, the social identity tradition (Tajfel \& Turner, 1979; Turner et al., 1987) has potential relevance for resilience theory and research. For instance, Tajfel's (1982) Social Identity Theory suggested that individuals gain positive self-esteem from their membership of relevant social groups, and identification with such groups is necessary to encourage successful action to advance their collective values, which enhances further social identification, and in turn boosts personal and collective self-esteem. The benefits for mental and physical well-being of such positive identification with one's relevant social groups are well documented (e.g. Jetten et al, 2012), and so there appear to be clear opportunities to incorporate broader social psychological approaches within resilience theory and practice.

\section{Emergent resilience?}

There is an abundance of evidence supporting the general concept of resilience and its broader social influences (see Ungar, 2012 for an overview), and most recently the concept of community resilience (or 'Sumud') in the face of chronic adversity has been explored in Palestine (Marie et al, 2018). However, studies of collective responses to disasters (e.g. Cocking, 2013; 2016;) have found that collective resilience and social support can also emerge from a shared sense of adversity ${ }^{3}$, and that communities affected by mass emergencies often develop creative and spontaneous ways of supporting each other both during the incident, and in its aftermath. This supports a seemingly counter-intuitive notion that in some contexts, resilience can emerge not just despite adversity, but also because of it. This has relevance for resilience within educational contexts, as the adversity that young people experience at school could be countered if it was perceived as a more shared experience, and given that all young people will experience some degree of adversity during their time at school, fostering a shared sense of adversity in educational contexts ${ }^{4}$ should be relatively straightforward. This could in turn encourage a sense of shared identification with their peers and general school environment, thus contributing to greater educational attainment and overall wellbeing.

3 This has been theorised as the Social Identity Model of Collective Resilience (SIMCR-Drury, 2012)

4 Shared stressors at school could include: bullying, exams, family problems etc. 


\section{The current study:}

The notion of emergent resilience from adverse childhood experiences is not new, but previous approaches have so far tended to consider it from an individual perspective, thus reducing the chances for spontaneous manifestations of collective support to be integrated within such models. Aranda \& Hart (2015) argued that 'tinkering with practice theory' p.355 can result in more resilient moves, but the focus was largely on parent and practitioner perspectives. Therefore, there is a need for more research into young people's experiences of school-based resilience programmes and mental health promotion initiatives. To address this gap, this study reports data from a wide-scale engagement exercise conducted in a county in the South of the UK that explored young people's views of health improvement and delivery in local schools, with a focus in this paper on their emotional well-being and resilience (EWR). It was expected that the scope of these studies would also contribute to attempts to contextualise resilience within broader social contexts, given the wide remit from a diverse range of young people with different experiences of adversity.

\section{Method:}

The research was approved by both the University of Brighton's and the relevant local authority's research ethics and governance procedures ${ }^{5}$. The engagement exercise explored the views and experiences of young people from 11-19 years old, with a view to informing provision of existing and future local health improvement services. It was designed to maximise involvement from participants, as it is recognised that research with young people should co-produce knowledge wherever possible (Hart et al, 2016). Therefore, an explicitly participatory approach was adopted to address the potential criticism that conventional research methodologies often exclude young people from the process. The participatory approach treats those involved as active agents in the research, thus increasing the chances that they will feel listened to. So, as an integral part of this project, Participant Steering Groups were held at regular intervals in local schools, whereby young people contributed to the project in a variety of different ways, including: feeding back on interview schedule design, data collection and analysis; and attending a concluding workshop that was held at the University of Brighton to disseminate the findings.

A total of 109 young people participated in a broad variety of data collection activities from three broad topics: (a) Emotional Well-being and Resilience (EWR); (b) Whole School Approaches (WSA) to health improvement; and (c) Sexual Health Improvement). For the study pertaining to resilience, 58 young people from (a) and (b) took part ${ }^{6}$, comprising: seven focus groups exploring 35 young people's views of the WSA scheme; and four focus groups and one individual interview with 23 participants exploring Emotional Wellbeing and Resilience (demographic data is presented in Table 1 below). Data was

5 Further details are available on request from the lead author.

6 Data was included from WSA as well as EWR groups, given that this approach explicitly considers emotional as well as physical well-being at school. 
collected in multiple locations including: local schools; a Pupil Referral Unit (PRU) ${ }^{7}$; and a youth club for young people who identify as LGBT or question their sexuality and/or gender identity. Each session lasted for up to a maximum of one hour, and explored the following broad topics: participants' familiarity and engagement with the term 'resilience'; possible individual and collective approaches to prevent stress and encourage resilience, and; the role that schools have in encouraging resilience and any services they could offer that were not currently available.

Table 1: Sample data for Whole-School Approach (WSA) and Emotional Wellbeing and Resilience (EWR)

\begin{tabular}{|c|c|c|c|c|c|}
\hline Age & $\mathrm{N}(\%)$ & Gender & $\mathrm{N}(\%)$ & Type of site & $\mathrm{N}(\%)$ \\
\hline $11-13$ & $21(36)$ & $\begin{array}{l}\text { Male } \\
\text { Female } \\
\text { Trans }\end{array}$ & $\begin{array}{l}32(55) \\
21(36) \\
5(9)\end{array}$ & $\begin{array}{l}\text { Academy } \\
\text { Community } \\
\text { college/ } \\
\text { school } \\
\text { Youth } \\
\text { Club/Centre } \\
\\
\text { Pupil Referral } \\
\text { Unit }\end{array}$ & $\begin{array}{l}32(55) \\
9(16)\end{array}$ \\
\hline Totals & 58 & & 58 & & 58 \\
\hline
\end{tabular}

\section{Data Analysis:}

Data collected from focus groups and individual interviews were audio recorded and transcribed verbatim (by a professional transcriber), with personally identifying information anonymised. The following conventions were used for transcription: $\mathrm{P}=$ Participant, I=Interviewer (where more than oneI1 I2, P1, P2 etc.); FG=Focus Group, II= Individual Interview; [...] text removed for clarity. Thematic Analysis (following Braun \& Clarke's (2006) guidelines) was used to analyse the dataset and following transcription, data were inspected to devise a preliminary coding structure as emerging themes were identified across the data set. Development of the final thematic categories was an iterative process and was informed and guided both by the project's initial key foci, but new themes also emerged from the data itself. Finally, analytical processes were triangulated to increase the findings' rigour. For instance, the lead author oversaw the interview exercises and data analysis relating to EWR, but also liaised with the other co-authors who were all involved in conducting interviews on topics relating to EWR and the WSA, as well as coding and analysis of data. Finally, the Principal Investigator of the overall engagement exercise oversaw the whole analytical process.

7 PRUs provide education to young people who have been excluded or cannot attend mainstream schools because of emotional, social, and/or behavioural difficulties. 


\section{Results:}

There was a broad variety of participants from different backgrounds, meaning that some topics attracted different perspectives, but there were also interesting commonalities across the sample. Therefore, the findings are categorised into four main overarching themes: participants' level of engagement with the term 'resilience' and associated constraints; individual strategies to promote more resilient outcomes; social and/or collective resilience strategies; and the role of schools/services in promoting resilience.

\section{Engagement with resilience}

Preliminary conversations focussed around young people's engagement with the concept of resilience, what they found stressful, and what helped them cope. Such engagement was not universal, and most participants were unfamiliar with the term when initially asked about it (the exception to this was the trans participants who used the term to describe how they coped with stigma and bullying). For instance, in the school and PRU interviews, only one participant was aware of the term:

I: Do you know what resilience is?

P: ...We used to talk about it in my old school like it was something massive.

I: What did they say?

P: They said it was the ability to bounce back...It's annoying though...people continue talking about it like we don't know what it means. Teachers talk to us like we're stupid...

I: Would you say, was it useful?

$P:$ No not at all. (PRU, FG)

So, whilst this participant reported a near text-book definition of resilience, they rejected its utility because of how it was delivered at school. This suggests that it wasn't the concept itself that was alienating, but that it was presented in a patronising way. This then generated some discussion of what being resilient might look like:

I: [Resilience] is talking about the ability to bounce back... so we're really interested in finding out... what you think about it.

P1: Like when you said bounce back, does it mean it'd be like getting back and that.

P2: On track, like turning your life round, it's never too late. (PRU, FG) 


\section{Individual resilience strategies}

Some participants showed insight and creativity into the various individual strategies they used to cope with stress, which could be considered as emergent resilient moves like those suggested by Hart et al (2007). For instance, this participant talked about their previous experiences at school in comparison with the PRU:

P: I used to be the one that kicked off and then I think the reason I started being naughty... was because everyone else was and then I came here I started being better behaved but now I keep on seeing people kicking off and that so it makes me think 'oh like that reminds me'... I used to find it quite fun cos it's like doing whatever you want really, just going on a little nutty one. But now every time, that's what stresses me out other people reminding me of what I was like and that and it just makes me want to do it again. (PRU, II)

So, while 'kicking off' was 'fun' and perhaps a personal strategy for resilience, it was also potentially problematic, as it resulted in interventions that could compromise future resilience (sanctions and eventual exclusion from his mainstream school). However, they now distanced themselves from such behaviour, and seeing others do it was stressful because it was a reminder of what they used to be like. They later described how within the constraints of a PRU it was still possible to explore creative ways of making resilient moves:

I: What other things help when you're hyper?

$P:$... just running around.

I: Do you get a chance to do that here?

P: Yeh earlier I was going absolutely mental sprinting up and down this corridor, sprinting all around the school, like jumping everywhere and like just until I got worn out and I couldn't run any more, they just let me... sprint up and down until I was worn out. (PRU, II)

Participants from mainstream schools reported more traditional methods of trying to achieve individual resilience, such as engaging in physical sports as a distraction tactic:

P: Well the rugby which I play... it's easier to take your anger out because you're just throwing people across the floor...

I: How does sport... help?

P: More like if you enjoy it you'll be more focused on that... say you're worrying about something, you'll forget about that for the time you're playing sport because you're enjoying that rather than focusing on your worries. (School, FG)

Participants from the trans youth club also reported a variety of creative individual strategies to achieve resilience, and showed some insight into the possible benefits: 
P1: I know how to meditate... like someone taught me a weird way of how to relax, it's quite a personal way...it releases loads of endorphins...

P2: I guess we do like a lot of activities... here like art and that but then... I take that home and if I'm feeling upset or whatever, then I'll do some drawing or some painting or just write down how I feel and that helps quite a lot if I'm feeling stressed. (Youth Club, FG)

\section{Collective resilience strategies}

Broader social influences were a common theme, and participants reported that a shared sense of identity, trust and social support were resources from which they drew upon to enhance their resilience. This links with recent evidence from social psychology (e.g. Jetten et al., 2012) demonstrating that mental and physical well-being can be improved by a strong sense of identity and connection with one's social group, and supports recent advice on well-being emphasising the role that peers can play in supporting pupils above and beyond the efforts of teachers (e.g. Weare, 2015). This perspective could also contribute towards countering traditional narratives (e.g. Hawton et al, 2012; Katz et al, 2013; Shenfield, 2015) that peer 'pressure' is largely a negative influence as it could encourage young people to engage in risky behaviours (self-harm, substance misuse, sexual promiscuity, etc.). Although sources of social support varied, participants were often explicit about the role they felt that their peers could play:

I: Do you find people help each other when people get stressed?

P: Yeh...like say another student is getting stressed, I think like being how close that they are I think another student would be able to help...more than the teachers will on certain situations. (PRU, FG)

Some schools also used a buddying scheme, whereby older pupils support younger ones, and this was rated positively by some;

P: They've had more experience throughout the years, cos we're only just into year 7 . They've started from all the way from the bottom so they've had experiences that they can tell us about and how to avoid them or help us with them. (School, FG)

Such buddying schemes can be useful in helping pupils through their transition from primary to secondary school, as there is a large body of evidence of the potential impacts such a transition can have on young people's emotional well-being (e.g. Allen 2014; Gniewosz et al, 2012; Pellegrini \& Long 2002), although James et al. (2014) argue that the evidence for peer-led schemes is mixed.

The sense of mutual support reported from participants' common experience of negative events (such as bullying) also illustrates how resilience can emerge from a shared experience of adversity. Recent evidence (e.g. Cocking, 2013; 2016) has shown how collective resilience can emerge from a common identity that results from a shared experience of adverse events (such as disasters, mass emergencies etc.). However, such processes are not unique to life-threatening emergencies, and the following extract shows how more mundane (but perhaps similarly stressful to those experiencing them!) adverse events can encourage the emergence of a shared sense of collective resilience and hope in humanity: 
P1: I've become friends with people I thought I would never have become friends with. Because of exams we'd always rely on each other and I think it's brilliant that even something that's so intimidating can just bring people closer together and shows that humans in general - in a time of need - will band together like our natural instincts would. (Youth Club, FG)

The positive outlook on humanity also has parallels with previous research into how notions of hope and community resilience can help those in disadvantaged communities to rise above the daily adversity they face (Ahmed et al, 2004; Mosavel et al, 2015), and how those facing individual challenges can become more resilient by supporting each other (Berliner et al, 2012).

\section{The role of schools/services in promoting resilience}

When asked about the support they received from teachers and other professionals, participants were more circumspect. This is not surprising given that Jetten et al. (2012) argued that social support is more likely to be perceived as being effective when coming from one's own in-group (e.g. peers). In such circumstances, teachers and other adults will be more likely to be perceived as an 'outgroup' and so may be less able to provide meaningful social support- however well-intentioned their efforts may be. The following extract illustrates the ambivalence some had about their teachers' attempts to support them:

I: Do you feel supported in helping to deal with your stress?

SEVERAL: No.

I: Does anyone feel supported?

P1: Sometimes.

I: Can you think of any examples when you do feel supported?

P1: When you have like a problem, like with another student or anything, you can go to the Head of Year... and they do help but they talk you through it to calm you down but they don't necessarily do anything about that problem.

\section{P2: They can only help you to a certain extent.}

P1: Yeh they can only help you understand the situation more but they don't actually do anything about it, just help you cope. (School, FG)

This illustrates the potential limitations with individual resilience frameworks, as there are limits to the support that school staff can offer, and there was a perception that this support focussed on merely helping participants cope with stress (as opposed to addressing its causes). This shows the need to also consider possible broader social perspectives when looking at strategies to improve individual resilience. If they are not considered, then the notion of resilience risks becoming little more than 'sociological Prozac' (Cocking, 2016, p.117) if it does not challenge existing structural inequalities, and instead expects young people to take personal responsibility for adjusting to adversity, something that was critiqued by Sherriff et al (2015). There were also more specific sub-themes that emerged from the overarching theme of young people's perceptions of institutional support, and these will be addressed in turn. 


\section{'Nobody listens to us'}

Common amongst all focus groups was the perception that school staff did not listen to them (and even if they did, nothing would change anyway), and this impacted upon their ability to deal with stress and achieve resilience. Participants kept returning to this issue throughout the discussions, with the topic also being used as an example of why they felt that their views were not being considered in a meaningful way:

\section{I: So, is it being listened to do you reckon?}

P: Yeh. But then I see it as like also you're being listened to for literally no reason, because nothing's going to happen, nothing of what you're saying is actually going to be taken into consideration and like actually being made into a change. So, it's just like pointless. (PRU, FG)

Furthermore, the following extract illustrates the difficulties young people felt were inherent in talking to teachers (especially if they were the source of the stress that they were experiencing), as well as their desire to be able to talk to other adults who weren't involved in teaching them:

P1: If you're in a bad mood... and the teacher's caused it...you can't really talk to other teachers about it because they might get annoyed with you...

I: Do you find there might be other things that could deal with the stress that aren't teachers?

P2: Get people in that aren't your teachers so you can slag them off.

I: Like me?

P2: Yeah. (School, FG)

Therefore, perhaps having adults that young people could talk to in less formal settings, and who are perceived as more 'neutral', could encourage greater trust and foster more opportunities for resilience to emerge (although there would still need to be clear guidelines about disclosure and safeguarding issues to prevent possible tensions with existing support networks in schools).

\section{Taking a lead}

Another common theme that emerged was the perception that schools need to provide leadership if they are to promote young people's resilience more effectively; something that is explicit in the National Institute of Clinical Excellence (NICE) guidelines on social and emotional well-being in schools (NICE, 2009), although there was also recognition of the possible associated complexities in this area. For instance, in the focus group with trans young people, participants felt teachers needed to take a lead in dealing with homophobic bullying, but also recognised the potential risks involved if they were also identified as being from the same marginalised group:

P1: I just think if teachers can't deal with it then kids aren't going to deal with it, you know... 
P2: The teacher has to be very brave themselves because teenagers... can be really quite vicious, with their comments so it can ruin a teacher's career... the class can be very homophobic to them which is why I think some teachers are afraid to come out.

P3: It takes a very confident person to come out.

P2: We've got a couple of openly gay teachers at our school and they get teased about it all the time. (Youth Club, FG)

In one of the school-based focus groups, participants also expressed frustration at what they felt was not only a failure to set a good example, but also inconsistencies in the teachers' own conduct:

P1: Everybody should follow the same rules including the teachers because they don't set a good example at the moment and it just encourages us to do the same. So, if they did it, if they follow the same rules maybe it would encourage us to as well...

P2: They teach us to be... ourselves but then...we're not allowed to express ourselves, so...taking nails as an example but that's what [name]'s into so that's what she does, whereas me I wore bright lipstick to school and I got an after-school detention. (School 3, FG)

\section{A resilient space}

A final theme that emerged was of a more practical nature- that of a 'safe space' where young people could choose to go to if they felt their resilience was compromised. However, the availability of such a space sometimes varied with the setting. For instance, participants in the PRU felt that such spaces were absent, meaning that female pupils created their own safe space in the toilets:

F: What they do here is, say that you're stressed; they don't really give you any time like...'go and try to calm yourself down'. They're literally just in your face.

I: Do you get a space like a physical space, a time out space that you can go to?

F: No

I: Do you think that would be useful?

F: Yeh.

M: But to be honest there probably isn't anywhere

F: Yeh I know because we don't have anywhere, like...if the girls are stressed they just tend to go to the girls' toilet. (PRU, FG)

The need for a resilient space in schools has been recognised in previous research (Hart and Green, 2014), as well as DfE (2015) guidance for school staff on mental health and behaviour in schools both highlighting the need for 'stress/relax' rooms (Aston, 2014 p.294) where young people can retreat to when necessary. However, this space should be separate from an isolation room that they can be taken 
to against their wishes as a sanction ${ }^{8}$. Finally, it is also worth considering that resilient spaces need not always be in schools, and indeed some would work better elsewhere. For instance, this participant from the trans youth group felt that merely having a space that they could retreat to where they didn't have to think about exams was beneficial:

I: What kind of things when you're at school might stress you out and how might you cope with them?

P: Exams, pressure like they always force it on you, they're always trying to make you the best and it's quite stressful. I can come here and just forget about the stress and troubles I go through at school... I do talk about my mocks a lot and they always support me and say, you will do well in them because you're quite smart. But then other than that we don't really go on to how we cope with stress because being here is enough to de-stress me. It's just the best place to be because 24:7 it's always exams exams and this 2-hour period is just my own time.

I: So, it's a kind of space away from the exams and it can be helpful just to not talk about it at all, just to give you that head space?

P: Yeh.

(Youth Club, FG)

\section{Discussion:}

The data presented in this paper provide a rich and diverse account of young people's views of their own emotional well-being and how they can become more resilient within educational contexts. Whilst participants' engagement with the concept of resilience varied, they were still aware of a variety of individual or collective strategies that they and/or their schools could pursue, and that such resilience could also emerge from a shared sense of adversity and mutual support. However, there was also a degree of cynicism as to whether such strategies would be implemented, and participants often felt that schools should take more of a lead in facilitating approaches that could help them cope with the stressors and strains that they might face. Overall, the findings provide support for the emerging consensus that resilience should be viewed as a dynamic social process rather than as a fixed individual attribute (e.g. Cocking, 2016; Hart et al, 2016). Furthermore, previous work (Drury, 2012; Cocking, 2013; 2016) suggesting that people can derive a sense of resilience from negative experiences is supported. This suggests that resilience may not simply endure despite adversity, but sometimes it can emerge because of such adversity, and resilient responses may not have developed in its absence. Nevertheless, it is worth remembering that it is not the negative experience itself that is the source of emergent resilience, and it is important to consider how those affected, respond to such adversity. So, if a shared sense of experience does not develop from exposure to adversity (e.g. if those affected respond with individual coping strategies and there is no shared sense of mutual support), then a sense of collective resilience would be less likely to emerge.

8 English secondary schools can take disruptive pupils to an isolation room for a 'limited period' DFE (2016) p.12 


\section{Implications and practical recommendations:}

Three main implications emerge from this study. Primarily, if educational initiatives that promote young people's emotional well-being are implemented, then they need to be engaged meaningfully with, and raise awareness of the potential benefits (and possible limitations) of the concept of resilience, as such initiatives will be of little use if young people are unaware of, or feel alienated from the term itself. Perhaps more work could be done with young people as to their views of the utility of 'resilience' and if it is not considered useful, then what they think might be a more useful concept. Furthermore, resilience approaches should be located within relevant practical, strategic and conceptual frameworks within the contexts where they are implemented, otherwise the concept risks becoming overused and meaningless. In terms of specific local impacts, it was encouraging to see that the local authority that commissioned the engagement exercise, later introduced a county-wide scheme implementing initiatives that related to recommendations drawn from our research.

Secondly, evidence from relevant theoretical perspectives could be applied to develop support networks within schools (the importance of social networks was highlighted by the Department for Children, Schools and Families, 2008). For instance, in this study a shared social identity developed through mutual peer support, and this was a resilient strategy that some participants reported as being beneficial to help them de-stress. Schools could explore the possible utility of such schemes (e.g. mentoring, buddying etc. ${ }^{9}$ ), and embed them within the Whole School Approach structure. These schemes can be low cost, and may be useful when integrating students into new and potentially alienating environments (such as the transition from primary to secondary schools- DfE, 2015b). Schools could also place greater emphasis on the role that informal peer support networks may play in maintaining young people's resilience, with some (e.g Young Minds, 2014) arguing that if such support schemes are to be effective, then they need to be designed and led by the young people themselves (with professional support available when necessary). This emphasis on the benefits of peer support in young people could contribute towards a growing recognition that social influence in young people's mental well-being need not focus primarily on the potentially negative aspects, as is often the current norm. For instance, the concept of social contagion, is often highlighted as a possible risk factor for selfharm and suicidality (Hawton et al, 2012; Katz et al 2013), and so peer support interventions in this area tend to be avoided (for fear that they could increase instances of self-harm).

Finally, on a broader strategic level, there is a need for meaningful dialogues with young people to involve them more in emotional well-being and resilience initiatives. This may involve exploring how resilience can be made relevant within the specific cultural ethos and/or physical context of educational environments. Part of this dialogue should focus on empowering young people to not only cope with the stressors they may face, but to also address the reasons why they may face adversity and how they might challenge it. However, the young people in our study also often expressed concerns that they did not feel they were listened to, and this raises a possible issue with the participatory approach that was adopted in this research. It is important for research with young people to have such approaches, and while this was viewed positively by participants (some stated that they liked being involved and having adults listen to them in an uncritical way), it does risk creating possible unrealistic expectations that all their views will necessarily be acted upon. Therefore, during the sessions, it was made clear that while participants were free to speak their minds without fear of being judged, the researcher did not necessarily have the authority to implement their wishes. However, they were re-assured that their

9 As suggested by Langford et al, (2014) and Weare (2015) 
views would be shared with school leadership, local authority decision makers, health improvement commissioners, and other delivery organisations- thus encouraging their involvement throughout the engagement process. So, in conjunction with this reassurance, schools should therefore be supported to develop strategies that address any possible concerns that young people feel their views are not considered important.

\section{Future research:}

This study shows that there is a need for more research into resilience programmes with young people. However, such research also needs to be clear what it is exploring, for as this study illustrated, researchers should not assume that young people will be familiar (or engage) with the concepts being presented to them. Therefore, there is a need for more participatory approaches that meaningfully involve them in the research throughout the entire process. Future research could consider in more detail what the terms of reference should be, how the concepts under exploration can be made relevant to participants, and if they are not familiar with them, what terms of reference would they prefer to see used. Furthermore, Cheng et al (2014) proposed there should be more research into how social support from multiple sources can predict young people's mental well-being, and so perhaps future studies could compare the different effects on well-being that social support from varying sources (such as peers, family, teachers etc.) could have. Such research would be in line with the Department of Health's (2015) call for more evaluation of peer support as a way of improving mental well-being in young people.

\section{Conclusion:}

While the concept of resilience can have important utility in educational contexts, there is also a pressing need to make it more relevant to young people's everyday experiences at school so that it can provide some tangible benefits into their lives and encourage the notion that their views are really being considered. If this can be done in a meaningful, age appropriate, and culturally relevant way, then there will be increased opportunities for young people to engage in strategies that maintain and enhance their emotional well-being, thus creating possibilities for interventions that will help ensure that schools can become spaces whereby young people's emergent resilience is encouraged and enhanced on both individual and collective levels. If such interventions are also considered within the broader social and collective contexts in which resilience can occur (and also be prepared at times to adopt a more critical approach to the concept of resilience), then young people will have a better chance of not only coping with, but also challenging and eventually overcoming the stressors and strains they may face on their pathway to adulthood.

\section{References:}

Ahmed R, Seedat M, Van Niekerk A \& Bulbulia S (2004) Discerning community resilience in disadvantaged communities in the context of violence and injury prevention. South African Journal of Psychology 34 (3): 386-408. 
Allen M (2014) Local action on health inequalities; building children's and young people's resilience in schools. Public Health England: London.

Aranda K, and Hart A (2015) Resilient Moves: Tinkering with Practice Theory to Generate New Ways of Thinking about Using Resilience. Health: An Interdisciplinary Journal for the Social Study of Health, IIIness and Medicine 14 (9): 355-371.

Aranda K, Zeeman L, Scholes J, \& Santa-María Morales A (2012) The Resilient Subject: Exploring Subjectivity, Identity and the Body in Narratives of Resilience. Health: An Interdisciplinary Journal for the Social Study of Health, Illness and Medicine 16 (5): 548-563.

Aston $\mathrm{H}$ (2014) An ecological model of mental health promotion for school communities: adolescents' views about mental health promotion in secondary schools in the UK. International Journal of Mental Health Promotion 16 (5): 289-307.

Berliner P, Larsen LN \& Soberon E (2012) Case study: Promoting community resilience with local values Greenland's Paamiut Asasara. In Ungar M (ed.) The Social Ecology of Resilience: A handbook of theory and practice. New York: Springer, pp 387-98

Bottrell D (2013) Responsibilised Resilience? Reworking Neoliberal Social Policy Texts. M/C Journal 16(5). http://journal.media-culture.org.au/index.php/mcjournal/article/view/708 (accessed 11/11/2017)

Braun V \& Clarke V (2006) Using thematic analysis in psychology Qualitative Research in Psychology 3: 77-101

Brooks F (2012) Life stage: School Years: Chapter 7 in Chief Medical Officer's annual report 2012. London: Department of Health.

Cheng Y, Li X, Lou C, Sonestein F, Kalamar A, Jejeebhoy S, Delany-Moretlwe, Brahmbatt H, Olumide A \& Ojengbede $O$ (2014) The association between Social support and mental health among vulnerable adolescents in five cities: Findings from the study of the well-being of adolescents in vulnerable environments. Journal of Adolescent Health 55. S31-S38.

Cocking C (2013) Collective resilience versus collective vulnerability after disasters- a Social Psychological perspective. In R. Arora (ed.) Disaster Management: A Medical Perspective. CABI: Oxford, UK.

Cocking, C (2016) Collective Resilience and social support in the face of adversity- evidence from Social Psychology in Kumar, U (ed.) The Routledge International Handbook of Psychosocial Resilience. Routledge, Taylor \& Francis: UK.

Department for Children, Schools and Families (2008) Children and young people in mind: The final report of the National CAMHS Review. London: DCSF.

Department for Education (2015) Mental health and behaviour in schools: Departmental advice for school staff. London: DfE. https://www.gov.uk/government/publications/mental-health-and-behaviour-inschools--2 (accessed 31/12/2017).

Department for Education (2016) Behaviour and discipline in schools Advice for Headteachers and school staff.https://www.gov.uk/government/uploads/system/uploads/attachment data/file/488034/Behavio ur and Discipline in Schools - A guide for headteachers and School Staff.pdf (accessed $11 / 11 / 2017)$ 
Department of Health (2015) Future in mind Promoting, protecting and improving our children and young people's mental health and wellbeing. http://www.gov.uk/government/uploads/system/uploads/attachment data/file/414024/Childrens Me ntal Health.pdf (accessed 11/11/2017).

De Lint W \& Chazal N (2013) Resilience and Criminal Justice: Unsafe at Low Altitude. Critical Criminology 21: 157-176.

Drury J (2012) Collective resilience in mass emergencies and disasters: a social identity model. In: Jetten J Haslam C and Haslam S A (Eds) The Social Cure: Identity, Health and Well-being (pp. 195-215). Hove, UK: Psychology Press,

Eames V Shippen C \& Sharp H (2016) Team of life- a narrative approach to building resilience in UK children. Educational and Child Psychology. 33 (2): 57-68.

Glasgow Centre for Population Health (2014) Resilience for public health: supporting transformation in people and communities. Glasgow: GCPH. http://www.gcph.co.uk/assets/0000/4197/Resilience Briefing Paper Concepts Series 12.pdf (accessed 31/12/2017).

Gniewosz B Eccles JS, and Noack P (2012) Secondary School Transition and the Use of Different Sources of Information for the Construction of the Academic Self-concept. Social Development 21 (3): 537-557.

Hart A, Blincow D, \& Thomas H (2007) Resilient Therapy: working with children and families. Hove, UK: Routledge

Hart A, Gagnon E, Eryigit-Madzwamuse S, Cameron J, Aranda K, Rathbone A \& Heaver B (2016) Uniting resilience research and practice with an inequalities approach. Sage Open. Oct-Dec 2016: 1-13

Hart A and Green S (2014) Fostering academic resilience: a short introduction to the pros and cons of specific approaches for schools. University of Brighton, UK. www.boingboing.org.uk/index.php/component/content/article/14-static-content/our-research/145schools-projects (accessed 11/11/2017)

Hawton K, Saunders K, O’Connor R (2012) Self-harm and suicide in adolescents. Lancet, 379: 2373-2382.

James A, Smith P, and Radford L (2014) Becoming grown-ups: a qualitative study of the experiences of peer mentors. Pastoral Care in Education 32 (2): 104-115.

Jetten J, Haslam C and Haslam SA (2016) (Eds) The Social Cure: Identity, Health and Well-being (pp. 195-215), Hove, UK: Psychology Press.

Katz C, Bolton SL, Katz LY, Isaak C, Tilston-Jones T \& Sareen J (2013) A review of school-based suicide prevention programmes. Depression and Anxiety, 30 (10): 1030-1045.

Langford R, Bonell CP, Jones HE, Pouliou, T, Murphy SM, Waters E (2014) The WHO health promoting school framework for improving the health and wellbeing of students and their academic achievement. Review prepared and maintained by The Cochrane Collaboration and published in The Cochrane Library Issue 4. John Wiley and Sons Ltd. 
Lyons C (2016) Strengthening personal resilience in East Sussex. Annual report of the director of public health 2015/16, Lewes, UK. http://www.eastsussexjsna.org.uk/JsnaSiteAspx/media/jsnamedia/documents/publichealthreports/2015 16/StrengtheningPersonalResiliencelnEastSussexHighRes. pdf (accessed 11/11/2017)

Marie M, Hannigan B \& Jones A (2018) Social Ecology of Resilience and Sumud of Palestinians. Health: An Interdisciplinary Journal for the Social Study of Health, Illness and Medicine 22 (1) 20-35

Marmot, M. (2010) Fair society, healthy lives: strategic review of health inequalities in England post-2010. London, Marmot Review. http://www.parliament.uk/documents/fair-society-healthy-lives-fullreport.pdf (accessed 11/11/2017)

Mosavel M, Ahmed R, Ports K, \& Simon C (2015) South African urban youth narratives: resilience within community. International Journal of Adolescence and Youth. 20 (2): 254-55.

National Institute for Health and Care Excellence (2009) Social and emotional well-being in secondary education. London: NICE https://www.nice.org.uk/guidance/ph20 (accessed 11/11/2017)

National Society for the Protection of Cruelty to Children (2014) On the edge. Childline spotlight: suicide., London, UK. NSPCC. https://www.nspcc.org.uk/globalassets/documents/research-reports/on-the-edgechildline-suicide-report.pdf (accessed 11/11/2017)

Pellegrini AD and Long JD (2002) A longitudinal study of bullying, dominance, and victimization during the transition from primary school through secondary school. British Journal of Developmental Psychology, 20(2), 259-280.

Public Health England (2014) Local action on health inequalities: building children and young people's resilience in schools. Health equity evidence review. London: UCL Institute of Health Equity. https://www.gov.uk/government/uploads/system/uploads/attachment data/file/355766/Review2 Resi lience in schools health inequalities.pdf (accessed 31/12/2017).

Rowe F, and Stewart D (2009) Promoting connectedness through whole school approaches: a qualitative study. Health Education 109 (5): 396-413.

Shenfield T (2015) Resisting peer pressure- how parents can help. Advanced Psychology: Child Psychology and parenting blog. http://www.psy-ed.com/wpblog/resisting-peer-pressure/ (accessed 11/11/2017)

Sherriff N, Coleman L \& Cocking C (2015) Engaging young people to inform health improvement commissioning and delivery in East Sussex: Final Report. University of Brighton. http://blogs.brighton.ac.uk/healthpromotionbrighton/files/2015/11/ESCC Final-Report Nov 1512afr8l.pdf(accessed 11/11/2017)

Stengård E \& Appelqvist-Schmidlechner K (2010) Mental Health Promotion Young People-an investment for the future. World Health Organisation, Denmark. http://www.euro.who.int/ data/assets/pdf file/0013/121135/E94270.pdf (accessed 11/11/2017)

Stewart-Brown S (2006) What is the Evidence on School Health Promotion in Improving Health or Preventing Disease and, Specifically, what is the Effectiveness of the Health Promoting Schools Approach? Copenhagen: World Health Organization Regional Office for Europe's Health Evidence Network (HeN), available at: $\underline{\text { www.euro.who.int/document/e88185.pdf }}$ 
Tajfel H, \& Turner JC (1979) An integrative theory of intergroup relations. In S. Worchel \& W. G. Austin (Eds.), Psychology of intergroup relations (pp. 33-47). Monterey, CA: Brooks-Cole.

Tajfel H (1982) Social identity and intergroup relations. Cambridge: Cambridge University Press.

Theron L (2016) The everyday ways that school ecologies facilitate resilience: Implications for school psychologists. School Psychology International 37(2) 87-103.

Traynor M (2018) Guest editorial: What's wrong with resilience. Journal of Research in Nursing23 (1) 5-8.

Turner JC, Hogg MA, Oakes PJ, Reicher SD, \& Wetherell MS (1987) Rediscovering the social group: A selfcategorization theory. Oxford, UK: Blackwell.

Ungar M (2012) The Social Ecology of Resilience: A handbook of theory and practice. New York: Springer

Weare K (2015) What works in promoting social and emotional wellbeing and responding to mental health problems in schools? London, National Children's Bureau. http://www.senplus.Itd.uk/wpcontent/uploads/2015/02/Promoting-Social-Emotional-Well-being-etc-NCB.pdf (accessed 11/11/2017)

Wells J, Barlow J, and Stewart-Brown S (2003) A systematic review of universal approaches to mental health promotion in schools. Health Education 103: 197-220.

Young Minds (2014) Report on Children, Young People and Family Engagement.

http://www.gmecscn.nhs.uk/attachments/article/196/Young Minds.pdf (accessed 11/11/2017).

\section{Authors biographical information:}

\section{Dr Chris Cocking:}

Chris Cocking is a Senior Lecturer at the School of Health Sciences, University of Brighton. He has a research background in social psychology, crowd behaviour and collective action, and is a member of the British Psychological Society (Social Psychology Section). He is a qualified mental health nurse with experience of working in child and adolescent mental health services (CAMHS). His current research interests include peer support collective resilience in young people with mental health issues.

\section{Dr Nigel Sherriff:}

Nigel Sherriff is a Principal Research Fellow in the School of Health Sciences. He is an accredited European Health Promotion Practitioner, a Chartered Psychologist, and an Associate Fellow of the British Psychological Society. His research interests are driven strongly by a social justice agenda, along with a desire for research to be collaborative and participatory with demonstrative social impact which ultimately tackles disadvantage and inequalities in health

\section{Dr Kay Aranda:}

Kay Aranda is a Reader in the School of Health Sciences at the University of Brighton. She has a long-standing involvement and research interests in gender, health and social inequalities and discrimination, having taught, worked and researched in both the voluntary sector and NHS in primary care, women's health and 
community nursing. She is currently working on an ESRC seminar series with civil society organisations exploring theories of social practice for understanding inequalities in health and care.

\section{Dr Laetitia Zeeman:}

Laetitia Zeeman has extensive experience in healthcare governance, clinical practice and higher education gained in the UK and Southern Africa. These roles act as foundation to her current research activities at the University of Brighton for the European Commission (Health4LGBTI) and Local UK Council, to promote the health and wellbeing of specific populations whilst recognising the strengths and abilities of people when they face adversity. Generating individual capacity is understood in the context of boarder systemic, policy and practice change needed to address inequity.

Funding information: The paper draws on insights gained from engagement and participation activities, commissioned by a grant ${ }^{10}$ from East Sussex County Council (ESCC), UK. This exercise aimed to provide greater understanding of the views and experiences of young people in relation to health improvement services and initiatives. ESCC developed the overall remit of the research and helped guide the work, with the authors developing and conducting the specific research exercises. The findings have been used by ESCC to help inform service changes and develop a transformational health improvement programme in school settings.

\footnotetext{
${ }^{10}$ Engagement with young people to inform health improvement commissioning for children, families and schools in East Sussex. PI Dr Nigel Sherriff. November 2014-June 2015
} 